This item was submitted to Loughborough's Research Repository by the author.

Items in Figshare are protected by copyright, with all rights reserved, unless otherwise indicated.

\title{
Development of a methodology for live capture and reuse of project knowledge in construction
}

PLEASE CITE THE PUBLISHED VERSION

\section{PUBLISHER}

(c) ASCE

\section{VERSION}

AM (Accepted Manuscript)

\section{LICENCE}

CC BY-NC-ND 4.0

\section{REPOSITORY RECORD}

Tan, Hai Chen, Patricia M. Carrillo, Chimay J. Anumba, Dino Bouchlaghem, John M. Kamara, and Chihoko Ueda. 2019. "Development of a Methodology for Live Capture and Reuse of Project Knowledge in Construction". figshare. https://hdl.handle.net/2134/4224. 
This item was submitted to Loughborough's Institutional Repository (https://dspace.lboro.ac.uk/) by the author and is made available under the following Creative Commons Licence conditions.

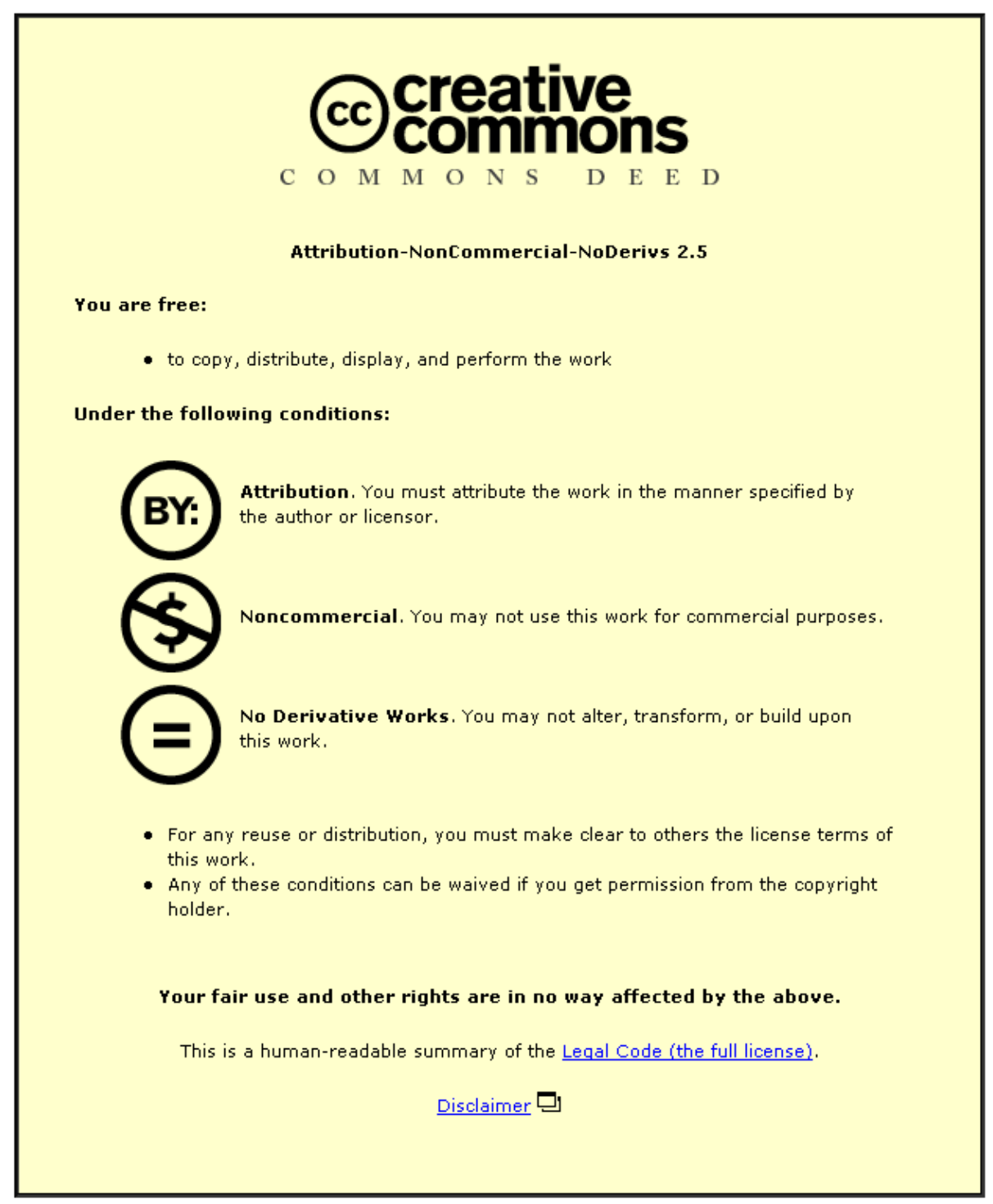

For the full text of this licence, please go to: http://creativecommons.org/licenses/by-nc-nd/2.5/ 


\title{
Development of a Methodology for Live Capture and Reuse of Project Knowledge in Construction
}

\author{
Hai Chen Tan ${ }^{1}$; Patricia M. Carrillo² ${ }^{2}$ Chimay J. Anumba, M.ASCE ${ }^{3}$; Nasreddine $^{4}$ (Dino) \\ Bouchlaghem; John M. Kamara ${ }^{5}$; and Chika E. Udeaja ${ }^{6}$
}

\begin{abstract}
The efforts to share and reuse knowledge generated on construction projects are undermined mainly by the loss of important insights and knowledge due to the time lapse in capturing the knowledge, staff turnover and people's reluctance to share knowledge. To address this, it is crucial for knowledge to be captured 'live' in a collaborative environment while the project is being executed and presented in a format that will facilitate its reuse during and after the project. This paper uses a case study approach to investigate the end-users' requirements for a methodology for the 'live' capture and reuse of knowledge, and the shortcomings of current practice in meeting these requirements. A methodology for the 'live' capture and reuse of project knowledge is then presented and discussed. The methodology, which comprises an Web-based knowledge base, an integrated workflow system (IWS) and a Project Knowledge Manager (PKM) as the administrator, allows project knowledge to be captured 'live' from ongoing projects. This also incorporates mechanisms to hasten knowledge validation and the dissemination of the knowledge once it has been validated.
\end{abstract}

\footnotetext{
${ }^{1}$ Research Associate, Department of Civil \& Building Engineering, Loughborough University, Loughborough, LE11 3TU, UK. Tel: +44 (0)1509-263171 extension 8745; Fax: +44 (0)1509-223982; E-mail: h.c.tan@lboro.ac.uk

${ }^{2}$ Professor, Department of Civil \& Building Engineering, Loughborough University, Loughborough, LE11 3TU, UK. E-mail: p.m.carrillo@lboro.ac.uk

${ }^{3}$ Professor, M.ASCE, Department of Civil \& Building Engineering, Loughborough University, Loughborough, LE11 3TU, UK. E-mail: c.j.anumba@lboro.ac.uk

${ }^{4}$ Professor, Department of Civil \& Building Engineering, Loughborough University, Loughborough, LE11 3TU, United Kingdom. E-mail: n.m.bouchlaghem@lboro.ac.uk

${ }^{5}$ Lecturer, School of Architecture, Planning \& Landscape, University of Newcastle Upon Tyne, NE1 7RU, UK.

${ }^{6}$ Research Associate, School of Architecture, Planning \& Landscape, University of Newcastle Upon Tyne, NE1 7RU, UK.
} 
CE Database subject headings: Knowledge-based systems; Construction management; Construction companies; Information technology (IT); Project management

\section{Introduction}

In the knowledge-based economy, the most important asset of organizations is knowledge (Stewart 1997). An organization's competitive advantage lies in the knowledge residing in the heads of its employees and the capability to harness the knowledge for meeting its business objectives. Given the growing importance of knowledge towards the success and even the survival of an organization, the significance of a systematic or organized knowledge management (KM) approach is being increasingly recognized. KMPG's (2003) survey results revealed that the knowledge management practice in the organizations surveyed had improved from one mainly characterized by the lack of an established implementation strategy in 1998, to one approaching a higher maturity level with greater board/management support in 2002/2003.

In the context of the construction industry, a survey of UK project-based organizations shows that about $50 \%$ of the respondents (majority were from the construction industry) noted that KM would result in new technologies and new processes that will benefit the organizations (Egbu 2002). This finding is supported by another survey of construction organizations which revealed that about $40 \%$ already had a KM strategy and another $41 \%$ planned to have a strategy within a year (Carrillo et al. 2003). Furthermore, about $80 \%$ also perceived KM as having the potential to provide benefits to their organizations, and some had already appointed a senior person or group of people to implement their KM strategy (Carrillo et al. 2003). However, despite this growing awareness of the importance of KM to the industry, there are limitations in the current practice for the capture and reuse of project knowledge. In particular, there are problems with the loss of knowledge due to the time lapse 
in capturing the knowledge, high staff turnover and reassignment of people (Kamara et al. 2003). To address these issues, it is crucial for the knowledge to be captured 'live' (i.e. once it is created or identified) in a collaborative environment during the course of the project. This paper presents the findings from six case studies conducted on the current practice and the requirements for the capture and reuse of project knowledge in the construction industry. It forms part of the work done in the research project 'Capture and Reuse of Project Knowledge in Construction' (CAPRIKON) which aims to develop an appropriate methodology for the 'live’ capture and reuse of project knowledge in construction. This paper starts with a review of knowledge capture and reuse, and related work. It then makes the case for 'live' capture and reuse of knowledge in construction projects before presenting the findings of the case studies undertaken. These findings are used to formulate a set of requirements for a KM methodology to address the shortcomings of current approaches. Finally, the details of the methodology developed are presented and discussed.

\section{Knowledge Capture and Reuse}

KPMG (1998) defines knowledge management as a systematic and organized attempt to use knowledge within an organization to transform its ability to store and use knowledge to improve performance. Knowledge management has a lifecycle that consists of some processes or stages. Different researchers have used different terms for the same knowledge management processes or stages (e.g. Davenport and Prusak 2000; Mertins et al. 2001; Bhatt 2001; and Rollett 2003). What differentiates each of these is the difference in perspective, focus and level of detail. Bhatt (2001) delineated the sequence of the knowledge management processes as: knowledge creation, knowledge validation, knowledge presentation, knowledge distribution and knowledge application. However, there is evidence that knowledge management processes may not exist in that linear sequence. Demarest (1997) noted that 
there can be some iterations between the knowledge management processes, and that some of these stages may exist simultaneously. The knowledge management process models also differ in the level of detail: some do not take into consideration the issue of knowledge obsolescence in knowledge management (e.g. Demarest 1997; Kululanga and McCaffer 2001) while others do not address the need to validate the knowledge. Four main KM processes, which have incorporated the notions of knowledge obsolescence and validation, are proposed based on the KM process models that have been developed within the context of construction (i.e. Robinson et al. 2001; Kululanga and McCaffer 2001): (1) Knowledge Capture; (2) Knowledge Sharing; (3) Knowledge Reuse; and (4) Maintain Knowledge.

\section{Knowledge Capture}

Knowledge capture comprises three sub-processes:

- Identifying and Locating Knowledge - This deals with the identification of the types/categories of knowledge to be managed, and the location of learning situations (Kamara et al. 2003) where most of the new knowledge is created and the people with the knowledge required.

- Representing and Storing Knowledge - This encompasses indexing, organizing and structuring knowledge (Robinson et al. 2002; Rollett 2003) into theme-specific knowledge areas, and authoring knowledge (Markus, 2001) in the standard or format specified with the details required, adding context to the knowledge depicting where the knowledge was generated and used, where the knowledge may be useful and the conditions for reuse (Davenport and Hansen 1999).

- Validating Knowledge - This is intended to ensure the credence of knowledge captured, and that the knowledge captured is stored with all the relevant contextual details and in the format required. 


\section{Knowledge Sharing}

This is about the provision of the right knowledge to the right person at the right time (Robinson et al. 2002; Mertins et al. 2001) or within the shortest time possible. This process can be passive (e.g. publishing a newsletter or populating a knowledge repository for users to browse), or active (e.g. 'pushing' knowledge via an electronic alert to those who need to know) (Markus 2001). Although the tools and methods used are dominated by information and communication technology (ICT) applications (Mertins et al. 2001), effective knowledge sharing is also underpinned by a supportive organizational culture and trust between the people involved (Newell et al. 2002).

\section{Knowledge Reuse - Adapting and Applying}

This covers the reuse of knowledge through the re-application of knowledge, such as the reapplication of best practice as mentioned by Szulanski (2000), and the reuse of knowledge for innovation with necessary adaptation or integration (Majchrak et al. 2004). The reuse of knowledge through adaptation involves re-conceptualizing the problem and searching for reusable ideas (i.e. knowledge), scanning and evaluating reusable ideas, analyzing the ideas in-depth and selecting the best idea, and developing fully the reused idea, which may ultimately lead to innovation (Majchrak et al. 2004).

\section{Maintain Knowledge - Archiving and Retirement}

Knowledge may become obsolete over time (Pakes and Schankerman 1979) due to the development of a discipline, and the employment of new information, rules and theories (Bhatt 2001). Maintaining knowledge covers reviewing, correcting, updating and refining 
knowledge to keep it up-to-date, preserving, and removing obsolete knowledge from the archive (Rollett 2003).

\section{Knowledge Management in Construction}

Knowledge management has always been a challenge to the construction industry. The construction industry is a predominantly project-based industry which operations are organized around projects (Kamara et al. 2000). Hence, most of the knowledge of the industry are generated in projects during the progress to deliver a custom-built facility in accordance to the client's requirements in addition to meeting client's own business objectives. The ability to manage the knowledge generated from the projects not only can help to prevent the 'reinvention of the wheel' and the repetition of similar mistakes, but also serve as the basis for innovation, overall improvement and sustaining competitive advantage. For a project-based organization to learn and expand its knowledge base, intra-project and inter-project learning (i.e. learning from within and across projects) are critical (Kotnour 2000) but difficult to achieve. This is often due to the tight timeframe of construction projects, and the lack of sufficient resources and standard work processes for managing project knowledge. Moreover, the fact that the project team either splits up or moves to another project after the completion of a project is also not conducive to the capture, sharing and reuse of knowledge across projects. As a result, knowledge loss is not an uncommon issue. The high staff turnover in the industry, which was $20.2 \%$ in 2003 in the UK (CIPD 2004), has also further aggravated the knowledge loss problem.

In view of these, a number of research projects have been undertaken to help improve the management of knowledge in the construction industry. However, the need for an approach which is capable of capturing project knowledge, irrespective of the type of project,

the type of construction organization and project phases, and particularly capturing the knowledge 'live’ (Kamara et al. 2003) has not been adequately addressed. The importance of 
a 'live' methodology to address the limitations of current practice is discussed in detail in the next section.

\section{The Importance of 'Live' Capture and Reuse of Project Knowledge Approach}

The imperative of 'live' capture of knowledge is supported by the recent survey of organizations involved in PFI (Private Finance Initiative) projects where the 'live' capture of knowledge is noted as crucial by $76 \%$ of construction organizations and $70 \%$ of client organizations (Robinson et al. 2004). Furthermore, the need for 'live' capture of knowledge is also being indirectly addressed by Whetherill et al. (2002). They assert that a construction organization's only sustainable advantage lies in its capability to learn faster than its competitors and the rate of change imposed by the external environment, and that there is a need to 'integrate learning within day-to-day work processes'. Kamara et al. (2003) have outlined the potential benefits of 'live' capture and reuse of project knowledge as follows:

- It facilitates the reuse of collective learning on a project by individual firms and teams involved in its delivery;

- It provides knowledge that can be utilized at the operation and maintenance stages of the assets' lifecycle;

- The 'live' methodology for knowledge capture proposed by Kamara et al. (2003) involves the members of the supply chain in a collaborative effort to capture learning in tandem with project implementation, irrespective of the contract type used to procure the project from the basis of both ongoing and post-project evaluation;

- It benefits client organizations with enriched knowledge about the development, construction and management of their assets; and

- It benefits the construction industry as a whole. Project teams would be enabled to manage better the subsequent phases of a project, to better plan future projects and to 
collaborate better with other organizations through the capture and transfer of learning from a previous phase or projects.

Other potential benefits identified include:

- It prevents knowledge loss due to time lapse in capturing the knowledge. This is supported by Ebbinghaus's (1885) and Linton's (1975) findings which reveal that the percentage of human memory retained on a set of data depletes over time and that the probability of forgetting an event (and knowledge) increases as time elapses;

- It maximizes the value of reusing the knowledge captured through 'live' reuse. The true benefit of capturing knowledge comes only when the knowledge is being used (McGee 2004), particularly if the knowledge is being reused 'live' after it has been captured. This is obvious when the benefit accrued through reusing the knowledge is time-related (e.g. leading to a saving of £x per day); and

- It enables knowledge to be disseminated for reuse as soon as possible (i.e. 'live') before the opportunities for reusing knowledge diminishes. This helps to seize every knowledge reuse opportunity.

\section{Research Methodology}

A case study approach was selected because it provided an in-depth insight into the current approaches for the capture and reuse of project knowledge within the case study companies and the end-users' requirements for knowledge capture and reuse. The case studies involved semi-structured interviews with 18 senior staff from six companies to ensure that a comprehensive view was obtained. The job titles of interviewees included: Group Knowledge Manager, Director of Business Development, Knowledge Researcher, IT Manager, Procurement Manager, Head of Research and Development, Company Partner and Managing Director. Each interview lasted one to two hours and was supplemented by presentations of 
the IT tools used for managing knowledge and sample documents showing the format used for capturing knowledge. The shortcomings of current practices and end-users' requirements identified were then analyzed to formulate the methodology for the 'live' capture and reuse of project knowledge in construction. Background information on the case study companies is presented in Table 1:

[Insert Table 1: Background of Case Study Companies]

\section{Case Study Findings}

The case studies explored: (1) The various types of reusable project knowledge which are important to be captured from construction projects; (2) The learning situations/events from which reusable project knowledge is created and can be captured; (3) Current approaches for the capture and reuse of project knowledge; and (4) The requirements for 'live' capture and reuse of project knowledge. This paper focuses on the findings of the latter two areas and an assessment of the capability of current approaches to facilitate 'live' capture and reuse of project knowledge.

\section{Shortcomings of Current Practice for the Capture and Reuse of Project}

\section{Knowledge}

$\mathrm{KM}$ tools used for the capture and sharing of knowledge can be categorized as $\mathrm{KM}$ techniques (non-IT tools) and KM technologies (IT tools) (Al-Ghassani 2003). Various KM techniques and technologies were being used by the case study companies. Some of the KM techniques, such as Communities of Practice, were also aided by KM technology. However, as knowledge management in the UK construction industry is still at an embryonic stage (Carrillo 2004; and Robinson et al. 2001), it is not surprising to find shortcomings in the current KM techniques and technologies, particularly in terms of the capability to facilitate 
the 'live' capture and reuse of project knowledge. The details of shortcomings of the eight most important and widely used KM tools identified from the case studies are as follows:

\section{Post Project Reviews (PPR)}

PPR is one of the most important and common approaches for the capture of project knowledge identified. However, the time lapse between the discovery and creation, and the capture and sharing of knowledge through PPR leads to the loss of important insights and does not allow the current project to be improved by incorporating the knowledge gained as the project progresses (Kamara et al. 2003). In addition, two major shortcomings of current PPR practice were identified in the case studies: first, in three out of the five cases, the learning captured was not being shared effectively and there was no established way to locate the learning embedded in reports for reuse. Secondly, the current practice of distilling the key learning captured in PPR into point form is too brief for understanding and efficient sharing of the knowledge captured.

\section{Communities of Practice (CoPs), Groupware and Forums}

Whilst powerful as a knowledge sharing tool, the shortcoming of CoPs, groupware and forum is their passive nature (i.e. if a question is not asked in the forum, the knowledge pertaining to the question is less likely to be shared). In addition, as Company A's forum was restricted to senior members of the company (mainly partners and associates), other members of staff who were excluded from the forum failed to benefit directly from the practice.

\section{Documentation of Knowledge}

Companies A and D's checklist-based design handbook and case studies of projects undertaken were criticized by their employees for lack of detail and reuse value. Companies 
C and F's practices (i.e. the creation of feedback notes which were accessible online and the maintenance of a knowledge base) were very mature and tested tools of documenting knowledge. However, there is no mechanism to ensure that the knowledge is captured 'live' or within a short time frame after its creation or generation. Furthermore, the knowledge captured by Company C's feedback notes is limited to that created or identified by the company while the views of other project team members are not captured.

\section{Training}

It was observed that training is more a practice for the trainers to share their knowledge with trainees. Furthermore, the time lapse between the capture of knowledge from a project by the trainer to the sharing of the knowledge in training is unlikely to meet the requirement of 'live' capture and reuse of project knowledge.

\section{Expert Directory}

Expert directory was used for the capture of knowledge on 'who knows what' only. It is a crucial tool for connecting the people who need a knowledge to the people with the knowledge, but not appropriate for the capture of knowledge.

\section{Custom-designed Software}

Tan et al. (2004) have identified various types of reusable project knowledge in construction, which need to be managed. Custom-designed software used for the capture of project knowledge were, however, narrow in scope and focused on specific types of project knowledge only. For instance, Companies B and D have custom-designed software which target only costing knowledge and knowledge about the performance of suppliers respectively. 
The capability of other KM techniques and technologies to facilitate the 'live' capture and reuse of project knowledge is summarized in Table 2.

[Insert Table 2 here]

The findings from the case studies revealed that although there are various KM techniques and technologies available for different $\mathrm{KM}$ sub-processes, none of the $\mathrm{KM}$ technologies or techniques represents a complete solution. The findings further revealed that both $\mathrm{KM}$ techniques and technologies have their strengths and shortcomings, and in fact complement each other. Therefore, a combination of KM technologies (e.g. a knowledge base) and KM techniques (e.g. project reviews and meetings, and PPR) appears to be the most pragmatic option to facilitate the 'live' capture and reuse of project knowledge in construction.

\section{Requirements for 'Live' Capture and Reuse of Project Knowledge}

The foremost requirement for the development of the methodology is the ability to facilitate the capture and access of project knowledge as soon as possible once knowledge is created or identified across geographically dispersed offices. In addition, the case companies also identified the following requirements important:

(1) Cost - The general consensus among the case study companies was that the methodology used for the capture and reuse of the reusable project knowledge should not incur significant additional cost to the companies;

(2) Workload - The companies emphasized that any methodology developed should not create significant additional workload to members of staff in view of their existing heavy workload. They also pointed out that the additional workload might not be covered by the worker's current job description or employment contract; 
(3) Legal Issues - Some companies prohibit their members of staff and collaborating companies from disclosing the information and knowledge learned to other organizations that are not involved in the project. A solution is required to ensure that the sharing, capture and reuse of knowledge from a project is not in breach of copyright and the conditions of contract;

(4) Accuracy - Any methodology developed must be capable of capturing and representing the knowledge accurately; and

(5) Representation of knowledge - The companies' main requirements for knowledge representation are summarized as follows:

- A standardized approach is required. The knowledge captured must be organized and represented in a logical and simple to understand way, and be readily accessible to others within the organization;

- Case studies or detailed explanation of the knowledge are to be provided to help others to understand and hence reuse the knowledge. This can be supplemented by video clips to capture the detailed explanation from the originator of the learning;

- A short description prepared to give the audience basic background information about a knowledge, and the characteristics of the project that are related to the context for the reuse of the knowledge;

- The conditions for reusing the knowledge must be made clear to the users; and

- Establishing convenient means, such as people's personal profile and knowledge network aided by custom-designed IT-systems, for people to communicate with each other and share their knowledge.

Discussion of the Requirements for 'Live' Capture and Reuse of Project Knowledge 
A methodology for the 'live' capture and reuse of project knowledge can be developed based on the various requirements identified from the case studies. The main requirements identified include: (1) Cost and workload; (2) Legal issues; (3) Accuracy of knowledge captured; (4) Representation of knowledge; and (5) Facilitating the capture and reuse of project knowledge as soon as possible once it is created or identified.

\section{Cost and Workload}

There are three cost components of a KM system that have to be managed and taken into consideration in the development of the methodology (Robinson et al. 2004):

- The staff costs (KM team component) associated with the roles and skills required for knowledge transformation;

- The organizational or (re)organizational costs (KM process component) associated with core and supporting business processes enabled, affected or re-engineered; and

- The KM infrastructure component costs associated with information and communications technologies (hardware and software), and the setting up or maintenance of people sharing networks, systems or techniques.

The following recommendations can help to reduce and to prevent additional cost in the aforementioned cost components:

- To keep the staff cost low, the 'live' knowledge capture and reuse methodology should avoid the need for additional staff and the creation of significant additional workload for existing staff as cost and workload are in fact interwoven. Therefore, it is also suggested that most of the relevant tasks and additional workloads created are handled by ICT;

- To reduce the organizational or (re)organizational costs, the methodology developed should build on existing practice if possible (i.e. integrated into something that people 
already do, such as meetings and reviews) for the capture of knowledge due to the need to re-engineer the current processes, or for a new process; and

- To reduce the KM infrastructure component costs, the application software developed as part of the 'live' knowledge capture and reuse methodology should be capable of running on existing ICT systems and platforms which are commonly used by construction organizations or that are readily available in the market.

\section{Legal issues}

To overcome the client's potential restriction on sharing information and knowledge with parties not involved in the project, the knowledge to be shared can be limited to those captured from the current project. The sharing of knowledge captured from other projects should be voluntary. An appropriate legal framework for 'live' knowledge capture and reuse needs to be developed and agreed between the project team members.

\section{Accuracy}

A validation mechanism is required to ensure that the knowledge entered is accurate, complete with all the details required in the specified format, important and reusable as a means to prevent knowledge overload. Company F's practice can be used as a reference, as the new knowledge captured has to be validated by a panel of experts before it is published on the company’s intranet for reuse.

\section{Representation of Knowledge}

A standard format for representing the reusable project knowledge captured was proposed and subsequently validated in the workshop conducted. This introduces the concept of a Project Knowledge File (PKF) which contains relevant project information and project 
knowledge that can be reused both during the execution (e.g. in subsequent phases) and after the completion of the project. The PKF covers:

a) Background information on the project - These include project title, project location; project sector; type of project; type of contract, start and completion dates, duration, companies involved, and date on which the knowledge is captured (which is included as an attempt to address the knowledge obsolescence issue).

b) Abstract - This is a short description of the knowledge captured.

c) Details - This is the detailed explanation of the knowledge so as to help others to understand and hence reuse the knowledge. Video clips, images and photographs can also be used to help explain the details about the knowledge.

d) Conditions for reuse - This spells out the condition(s) for reusing a particular knowledge entry.

e) Reference - This contains the reference to other relevant knowledge captured in the system, project documents, publications (e.g. books and reports), websites and people, where further details may be obtained.

In addition, a knowledge map and an index should be provided to give users an overview of the knowledge available.

\section{Enabling Technologies and Techniques}

The essence of the 'live' capture and reuse of project knowledge methodology lies in allowing users at different locations to enter and access the knowledge captured in real-time. Given the main strength of Web-based KM technologies (such as groupware, expert directories and knowledge bases) is their capability to connect distant offices together, provide fast access and location of knowledge captured, facilitate sharing of knowledge, and provide huge knowledge storage space, they are an integral element of the methodology for 
the 'live' capture and reuse of project knowledge. Among the KM technologies available, a web-based knowledge base seems to be the current practice closest to meeting the requirements identified. The reasons are as follows:

- No significant additional cost: A Web-based knowledge base can run on existing systems and platforms commonly used by most of the construction organizations. This eliminates the chances of incurring significant additional cost for the implementation of the methodology;

- No significant additional workload created: The only requirement is the need to enter project knowledge into the knowledge base;

- Accuracy of knowledge ensured: A mechanism can be built into the knowledge base for monitoring the validation of knowledge submitted as a means of ensuring its accuracy; and

- Allowing a standard format for representing project knowledge to be specified: Another built-in mechanism can be created to ensure that project knowledge is entered in accordance with the format developed.

A web-based knowledge base can be supplemented by PPR. PPR provides an opportunity for project team members from different organizations to share and even explicate their tacit knowledge through the face-to-face interactions facilitated before the team dissolved. In addition, the discourse amongst the project team members in PPR may lead to innovation and better idea than that can possibly be captured from an individual. This is crucial as everyone only knows bits of the whole story about a project (Kerth 2000). Therefore, PPR can help to ensure that a more complete set of project knowledge is being captured than through knowledge base alone. The main shortcomings of the PPR identified from case studies are: (1) its susceptibility to knowledge loss problem due to time lapse in capturing knowledge, and (2) the lack of an established format for the representation and a mechanism for sharing 
knowledge captured. The former shortcoming can be addressed by the attempts to capture project knowledge from routine project meetings (which are conducted at weekly or biweekly basis) and project reviews conducted at various project stages in addition to PPR. For the latter shortcoming, it is resolved by using the web-based knowledge base for the representation and sharing of knowledge captured from PPR.

\section{A Methodology for the 'Live' Capture and Reuse of Project Knowledge in Construction}

Based on the findings from the case studies, a methodology for the 'live' capture and reuse of project knowledge has been developed. The proposed methodology attempts to capture reusable project knowledge generated from the various learning situations once the knowledge is created or identified (i.e. 'live') through project reviews/meetings and individuals. The methodology comprises:

- A Web-based knowledge base - This is where the Project Knowledge File (PKF) of a project is stored. The knowledge base will run in the project extranet environment where only designated users from organizations collaborating in a project can gain access into the system;

- A Project Knowledge Manager (PKM) - This is a role, normally charged to a planning supervisor, project manager or other designated person, to manage the knowledge base (i.e. the development of a Project Knowledge File for a project) and the Integrated Workflow System (IWS); and

- An Integrated Workflow System (IWS) - This delineates, executes and monitors the mechanism for the capture, validation and dissemination of the project knowledge captured. A Project Knowledge Manager (PKM) may configure the IWS to suit individual requirements of the project. 
The details of the 'methodology for the 'live' capture and reuse of project knowledge, and how the PKM, IWS and knowledge base interact with each other, are depicted in Figure 1. [Insert Figure 1: Methodology for the 'live' capture and reuse of project knowledge in construction]

\section{Block 1: Integrated Workflow System and PKM}

The PKM first needs to enter details of the project (e.g. project title, duration and location) and to configure the Integrated Workflow System. The configuration covers:

a) The intervals at which the reminders will be sent to all users reminding them to enter any new knowledge gained;

b) How many days in advance of the routine meetings/reviews the tool should send the reminder to the Project Knowledge Manager (PKM); and

c) The preferred option for knowledge validation.

\section{Block 2: Capture knowledge from Group}

The PKM will be responsible for including the capture of reusable project knowledge as an agenda item in the routine project meetings/reviews. A template is developed to ensure that the project knowledge is captured in the stipulated format of the knowledge base. During the meetings/reviews, the learning captured since the previous meeting/review is discussed and the details agreed. This can then be entered into the system after approved.

\section{Block 3: Capture knowledge from individuals}

All knowledge workers involved in the project will be assigned a login name and password to access the system. This allows them to enter their knowledge into the software tool once the knowledge is gained or identified (i.e. 'live'), or at anytime which is convenient to them. 


\section{Block 4: Capture of the rationale for making changes to documents}

The findings of the case studies revealed that the rationale for making changes to project documents (such as engineering drawings) is important reusable project knowledge. The system will provide a summary of the number of changes made to the project documents which the PKM will check at predetermined intervals. When there is a project document for which the number of changes made to it is well above average, a procedure for the capture of the rationale for making the changes to the document will be invoked. The author of the project document will be required to provide the necessary details. Similar to the knowledge submitted by individuals, the rationale for changes made may be subject to validation before it can be disseminated.

\section{Block 5: Validation}

Validation is essentially the review of the knowledge captured by a group of designated people. The knowledge captured from a group (i.e. from meetings and reviews) is deemed to have been validated in the meeting or review, whereas the knowledge submitted by individuals may need to be validated prior to reuse. However, at the organization's discretion, the validation process may be omitted for knowledge submitted by their experts and very experienced staff. The validation mechanism of the system is triggered once new knowledge is submitted into the system by individuals. Two knowledge validation routes are provided:

a) Validation of knowledge submitted in the routine meetings or reviews: The knowledge submitted by individuals since the last meetings/reviews will be discussed in current meeting/review. The PKM will be responsible for deleting the knowledge from the system if the knowledge is rejected, or updating the status of the knowledge from 'draft' to validated knowledge in the system if the knowledge is approved; and 
b) Online Validation: All the project participants or designated people/experts will be requested by the system to take part in the process within the predetermined deadline. The system will monitor the progress and reminders will be sent if there is any delay in response on the part of the users. Some options for validating knowledge are provided. These include: (1) rating-based; (2) majority opinion-based; and (3) comment-based options. For the first two options, the system will decide to either validate or remove a knowledge based on the average rating given, or the majority's opinion on whether or not a knowledge should be approved. For the comment-based option, it requires the PKM to validate a knowledge or otherwise based on the comments received. An option is also provided to allow the validation mechanism to be bypassed. However, this option is not recommended as it may lead to problems such as 'not very important knowledge' being included in the Project Knowledge File.

The author(s) of the knowledge will be informed about the status of the knowledge submitted (i.e. rejected or accepted) together with the rating and comments (if any) given by others.

\section{Block 6: Project Knowledge File (PKF)}

Once new knowledge is added, the details of the knowledge and other information such as the details of the project will be captured in the PKF. The users have the options to have an overview of all the knowledge captured in the PKF (e.g. through the display of high-level information of the knowledge in a table or index page) and to access the details of knowledge. The details of knowledge captured include the background information of the project, and abstract, details, conditions for reuse, photos, video clips, relevant documents and references.

\section{Block 7: Dissemination and Reuse}


Knowledge is disseminated once it has been validated via email, although users can also access the knowledge from the knowledge base. The users have the option to either search for the knowledge required using a simple Google ${ }^{\mathrm{TM}}$-like search or an advanced search function. The latter option allows the knowledge to be searched based on keyword, rating given by others in validating the knowledge, project details (e.g. project title, type of contract and location) etc. and any combination of these.

All the project knowledge captured from a project will be recorded in a designated file, i.e. the Project Knowledge File (PKF), which is maintained throughout the duration of a project. All project team members can retain a copy at the end of a project. An overview of the processes involved for the capture and sharing of reusable project knowledge is depicted in Figure 2.

[Insert Figure 2 here]

\section{Conclusions}

The importance of the 'live' capture and reuse of project knowledge approach in construction has been identified. The shortcomings of current approaches for the capture of knowledge, end-users' requirements for the development of the methodology for 'live' capture and reuse of project knowledge identified, the format for representing knowledge, and the details of the methodology developed have been discussed. The case studies undertaken showed that post project reviews, communities of practice, documentation of knowledge, training, groupware, custom-designed software and 'Expert Directory' are the main KM tools used for knowledge capture and reuse. The case study companies also used a blend of different KM tools for managing their knowledge as there is currently no single KM tool capable of meeting all the KM requirements. In terms of facilitating the methodology for 'live' capture and reuse of project knowledge, the major shortcomings of the current practices identified are: 
- $\mathrm{KM}$ techniques (such as post project reviews and meetings) are mainly good in capturing project knowledge from people but are inadequate in facilitating 'live' sharing of the knowledge across distant offices;

- Some KM technologies (such as a Web-based knowledge base and extranets) are important in enabling 'live' sharing of project knowledge, but they still either lack an established mechanism to ensure that knowledge is captured 'live' from a project or an appropriate format for representing the knowledge captured; and

- Some tools are narrow in scope and only focus on the capture of specific types of project knowledge (e.g. the custom-designed software).

Through the case studies, various end-users' requirements for the development of the 'live' methodology were identified. These are:

- No significant additional cost;

- No significant additional workload to be created;

- Accuracy of knowledge must be ensured; and

- Having a standard format for representing project knowledge.

The findings of the case studies suggested that a combination of $\mathrm{KM}$ technologies (particularly a knowledge base) and KM techniques (i.e. capturing project knowledge through project meetings/reviews) would be the most pragmatic option in fulfilling the requirements for the 'live' capture and reuse of project knowledge methodology. A methodology for the 'live' capture and reuse of project knowledge was developed based on the findings from the case studies. The methodology comprises mainly:

- A Web-based knowledge base;

- A Project Knowledge Manager (PKM) who is the administrator of the system; and 
- An Integrated Workflow System (IWS) depicting how reusable project knowledge is captured from project meetings/reviews and individuals, and how knowledge is validated and shared subsequently.

Project knowledge is captured from project meetings and reviews conducted at various project stages. This allows the collective knowledge of the organizations involved in the project to be captured in a collaborative environment. The knowledge captured from project meetings/reviews and individuals is then stored and disseminated through the Web-based knowledge base. Further work on the research will involve the development of prototype software to support the methodology. This will then be followed by detailed testing and validation of the software prototype, and further refinements and improvements.

\section{Acknowledgements}

The authors would like to thank EPSRC for funding and industrial collaborators for their collaboration on this project.

\section{References}

Al-Ghassani, A. M. (2003). “Improving the Structural Design Process: A Knowledge Management Approach.” PhD thesis, Department of Civil and Building Engineering, Loughborough University, Loughborough, U.K.

Bhatt, G. D. (2001). “Knowledge management in organizations.” J. Knowledge Management, 5(1), 68-75.

Carrillo, P. M. (2004). “Managing knowledge: lessons from the oil and gas sector.” Construction Management and Economics, 22(6), 631-642. 
Carrillo, P. M., Robinson, H. S., Anumba, C. J., and Al-Ghassani, A. M. (2003). “IMPaKT: A Framework for Linking Knowledge Management to Business Performance.” Electronic Journal of Knowledge Management, 1(1), 1-12.

CIPD (2004). Recruitment, retention and turnover 2004: A survey of the UK and Ireland, Chartered Institute of Personnel and Development, UK.

Davenport, T. H., and Hansen, M. T. (1999). “Knowledge Management at Andersen Consulting.” Case No. 9-499-032, Harvard Business School Press, Boston.

Davenport, T. H., and Prusak, L. (2000). Working Knowledge: How Organizations Manage What They Know, Harvard Business School Press, Boston.

Demarest, M. (1997). “Understanding Knowledge Management.” Long Range Planning, 30(3), 374-384.

Ebbinghaus, H. (1885). “Uber das Gedachtnis.” Leipzig, Dunker. Translated by Ruger, H. A., and Bussenius, C. E. (1913). “Memory: A Contribution to Experimental Psychology.” Teachers College, Columbia University, US,

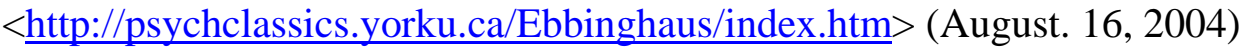

Egbu, C. (2002). “Knowledge Management, Intellectual Capital and Innovation: Their Association, Benefits and Challenges for Construction Organizations.” Proc., 10th International Symposium on Construction Innovation and Global Competitiveness, CRC Press, Ohio, US, 57-70.

Kamara, J. M., Anumba, C. J., Carrillo, P. M., and Bouchlaghem, N. M. (2003). “Conceptual Framework for Live Capture of Project Knowledge.” Proc., CIB W078 International Conference on Information Technology for Construction - Construction IT: Bridging the Distance, CIB, Waiheke Island, New Zealand, 178- 185. 
Kamara, J. M., Anumba, C. J., and Carrillo, P. M. (2000). “Integration of Knowledge Management within Construction Business Processes.” Proc., National Conference on Objects and Integration, Building Research Establishment Ltd., Watford, UK., 95-105. Kerth, N. (2000). “The ritual of retrospectives: how to maximize group learning by understanding past projects.” Software Testing \& Quality Engineering, 2(5), 53-57.

Kotnour, T. (2000). “Organizational learning practices in the project management environment.” Organizational Learning, 17(4/5), 393-406.

KPMG (1998). Knowledge Management Research Report 1998. KPMG Management Consulting.

KPMG (2003). Insights from KPMG's European Knowledge Management Survey 2002/2003. KPMG Knowledge Advisory Services.

Kululanga, G. K., and McCaffer, R. (2001). “Measuring knowledge management for construction organizations.” Engineering, Construction and Architectural Management, 8(5/6), 346-354.

Linton, M. (1975). “Memory for real-world events.” Explorations in cognition, D. A. Norman, and D. E. Rumelhart, eds., W.H.Freeman, San Francisco, 376-404.

Majchrzak, A., Cooper, L. P., and Neece, O. E. (2004). “Knowledge Reuse for Innovation.” Management Science, 50(2), 174-188.

Markus, M. L. (2001). “Toward a Theory of Knowledge Reuse: Types of Knowledge Reuse Situations and Factors in Reuse Success.” J. Management Information Systems, 18(1), 57-93.

McGee, K. G. (2004). Heads up: How to Anticipate Business Surprises and Seize Opportunities First, Harvard Business School Press, Massachusetts.

Mertins, K., Heisig, P., and Vorbeck, J. (2001). Knowledge Management: Best Practices in Europe, Springer, Berlin. 
Newell, S., Robertson, M., Scarbrough, H., and Swan, J. (2002). Managing Knowledge Work, Palgrave, Basingstoke, Hampshire.

Pakes, A., and Schankerman, M. (1979). “The Rate of Obsolescence of Knowledge Research Gestation Lags, and The Private Rate of Return to Research Resources.” National Bureau of Economic Research Working Paper No. 346, National Bureau of Economic Research, Cambridge, US.

Robinson, H. S., Carrillo, P. M., Anumba, C. J., and Bouchlaghem, N. M. (2004). Investigating Current Practices, Participation and Opportunities in the Private Finance Initiatives (PFI): A Survey of Construction and Client Organizations, Department of Civil and Building Engineering, Loughborough University, Loughborough, U.K.

Robinson, H. S., Carrillo, P. M., Anumba, C. J., and Al-Ghassani, A. M. (2001). “Perceptions and barriers in implementing knowledge management strategies in large construction organizations.” Proc., RICS Foundation Construction and Building Research Conference- COBRA 2001, RICS Foundation, Glasgow, U.K., 451-460.

Robinson, H. S., Carrillo, P. M., Anumba, C. J., and Al-Ghassani, A. M. (2002). “Knowledge Management for Continuous Improvement in Project Organizations.” Proc., 10th International Symposium on Construction Innovation in Project Organizations, CIB 65, Ohio, US., 680-697.

Rollett, H. (2003). Knowledge Management: Processes and Technologies, Kluwer Academic Publishers, Boston.

Stewart, T. A. (1997). Intellectual Capital: The new Wealth of Organizations, Doubleday, New York.

Szulanski, G. (2000). “The Process of Knowledge Transfer: A Diachronic Analysis of Stickiness.” Organizational Behavior and Human Decision Processes, 82(1), 9-27. 
Tan, H. C., Udeaja, C. E., Carrillo, P. M., Kamara, J. M., Anumba, C. J., and Bouchlaghem, N. M. (2004). Knowledge Capture and Re-use in Construction Projects: Concepts, Practices and Tools, Department of Civil and Building Engineering, Loughborough University, Loughborough, U.K.

Whetherill, M., Rezgui, Y., Lima, C., and Zarli, A. (2002). "Knowledge Management for The Construction Industry: The E-COGNOS Project.” ITCon, 7, 183-196. 
Table 1: Background of Case Study Companies

\begin{tabular}{clcr}
\hline Company & \multicolumn{1}{c}{ Company background } & Number of & Annual revenue (£) \\
employees & & \\
\hline A & Design Consultant & 80 & $£ 4.3 \mathrm{M}$ \\
B & Design Consultant & 850 & $£ 403 \mathrm{M}$ \\
C & Engineering Consultant & 7000 & $£ 61 \mathrm{M}$ \\
D & Management Consultant & 1200 & $£ 2 \mathrm{M}$ \\
E & Project Extranet Service Provider & 31 & $£ 1860 \mathrm{M}$ \\
F & Water Company & 18000 & \\
\hline
\end{tabular}


Table 2: Capability of other KM techniques and technologies to facilitate the 'live' capture and reuse of project knowledge

KM Technique/Technology

Team meetings, road shows,

presentations and workshops

Reassignment of people

Recruitment

External sources of knowledge

Project extranets
Facilitate 'live' capture and reuse?

No. The time lapse in the capture and sharing of knowledge between the knowledge provider and recipient is too lengthy

No. It is also undermined by staff turnover

No. It is a time consuming process

No. It is just an additional source of general project knowledge.

No. No special mechanism is created in the project extranet studied for the capture of project knowledge

Preparation of standard reusable details No. It is only viable for companies with high proportion of similar type (e.g. drawings \& specifications) of project in order to justify the time and other resources utilized

Research \& development, and No. The research carried out is mainly aimed at creating new knowledge team knowledge. No established way to share the knowledge created.

Partnership-like arrangements \& No. The fact that the companies working in a project may actually research collaboration with other compete in another project has also undermined the sharing of companies knowledge (Kamara et al, 2003)

Succession management \& mentoring No. It is mainly aimed at preparing a person to take up a particular position or tasks rather than the capture and reuse of knowledge 


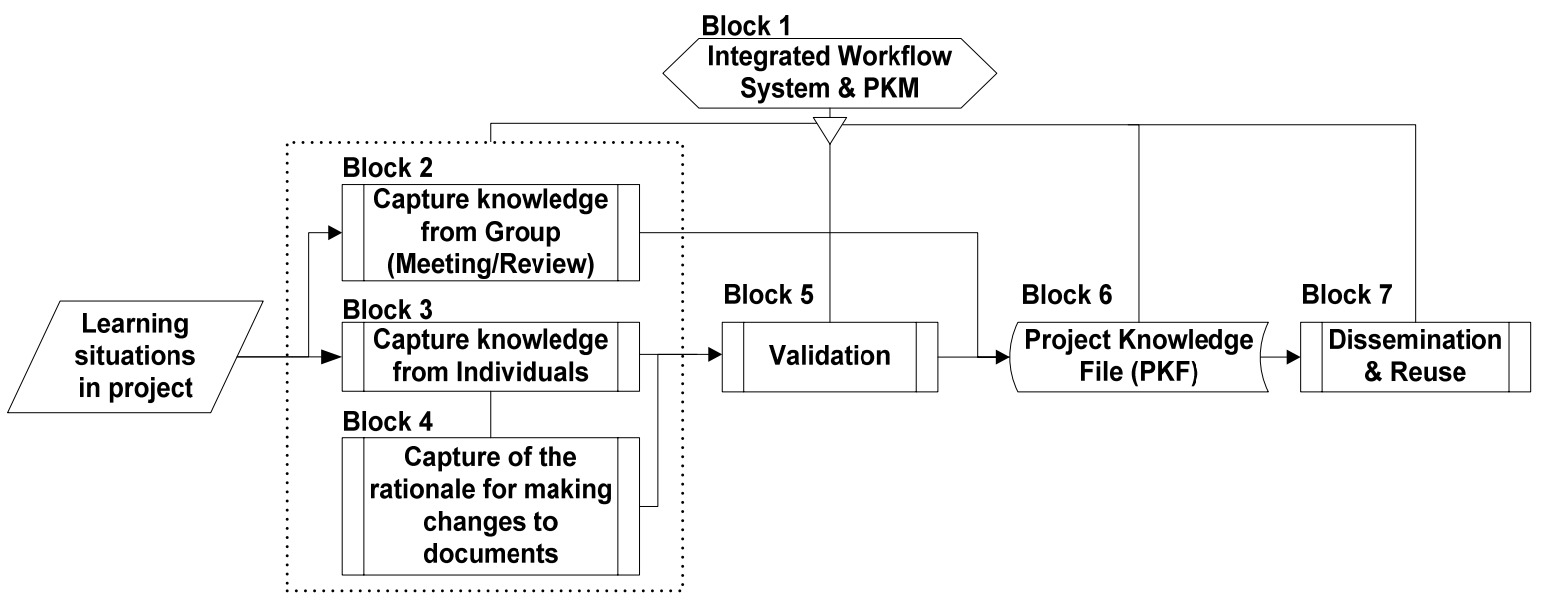

Figure 1: Methodology for the 'live' capture and reuse of project knowledge in construction 


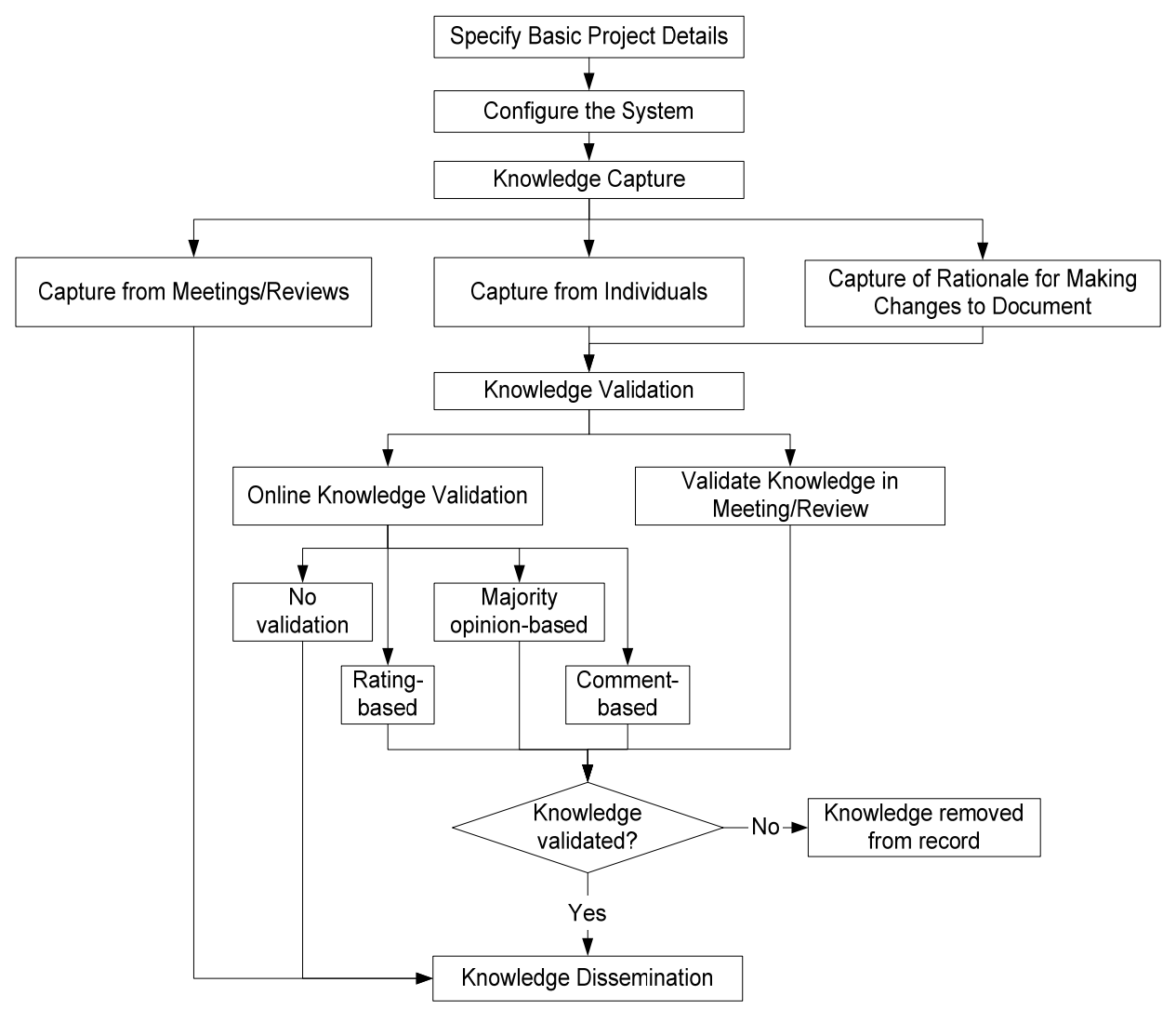

Figure 2: Simplified Integrated Workflow System (IWS) depicting the procedures involved for the capture and reuse of reusable project knowledge 